\title{
ABSTRACT ACCEPTANCES VERSUS CONFERENCE PRESENTATIONS IN GLOBAL PHARMACOLOGY CONFERENCES: SPECIAL REFERENCE TO AFRICAN PARTICIPATION
}

\section{Theresa A John}

Pharmacology, Therapeutics and Toxicology, Lagos State University College of Medicine, Nigeria

Background: The profession of scientists, especially as applied to research and development, is important for African and other countries. Are scientists constrained in attending scientific conferences? We hypothesised that the numbers of abstracts accepted for presentation are significantly greater than the numbers of corresponding presentations in pharmacology conferences.

Methods: We investigated poster presentations at 3 international pharmacology conferences: the 17th World Congress of Basic and Clinical Pharmacology (WCP 2014), Cape Town, South Africa; the 7th European Congress of Pharmacology (EPHAR 2016), Istanbul, Turkey; and the XXXIXth Annual Conference of the West African Society for Pharmacology (WASP/SOAP 2016), Kumasi, Ghana and a few other African conferences to find out if scientists were presenting their posters as expect according to the official programme. The poster sessions were visited at the times stipulated by the organizers for the presenters to be stationed by their posters and measures were taken to ensure missing posters were not placed elsewhere or at a wrong time. Posters were marked as seen irrespective of the presenters being present or not present.

Results: Amongst the conferences investigated (Figure 1), percent poster presentations was highest for the European Congress of Pharmacology; $>95 \%$ of the attendants were from affluent European countries. The lowest percent poster presentations was for the West African Society for Pharmacology, WASP2016; 100\% of the attendants were from developing West Africa. The World Congress, WCP2014, which embraced the whole world, developing and developed, had a percentage poster presentation similar to the average of the highest and the lowest. There was strong positive correlation, $r=0.0945$, between the arrays of numbers of seen and numbers of unseen posters for the three conferences showing the bigger the conference the bigger the number of failed submissions. The significance of this by one tailed paired t-test is $\mathrm{p}=0.0575$.

Conclusion: The present investigation shows that, globally, a non-significant number of scientists that submit abstracts fail to present at conferences. There appears to be a marked difference between global and African international conference participation after acceptance of abstracts and this needs to be investigated. Could this be in local financial support? 